\title{
Creativity and liking Republicans: Ideology or outgroup support?
}

\author{
RUSSELL EISENMAN \\ McNeese State University, Lake Charles, Louisiana
}

\begin{abstract}
Liking for Democrats and Republicans was indicated by 52 freshman and sophomore university students, who were also tested for creativity by choosing polygons differing in complexitysimplicity. Previous research has shown that creative people tend to prefer complexity. Creative students liked Republicans to a significantly greater extent than did noncreative students. There was no significant difference with regard to liking Democrats. The results support a liking-ofoutgroups explanation rather than an explanation based on political ideology.
\end{abstract}

A neglected area of research is political preferences in relationship to creativity. This study investigated liking or disliking of Democrats and Republicans, as related to creativity, which was measured by score on preference for complexity-simplicity in polygons. Complexity preferences have been shown to be related to creativity from the research of Barron (1990), who used the BarronWelsh Art Scale, to recent work by Eisenman (1991a, $1991 \mathrm{~b}, 1992$, in press) using the polygons utilized in the present study.

There are two obvious explanations of the possible relationship between creativity on the one hand and political preference on the other. If political ideology is the basis of choice, we should expect that creative students would dislike Republicans, since the Republican ideology seems too conservative, most of the time, to appeal to creative people. Creative people tend to be radical, experimenting, and risk-taking (Barron, 1990; Eisenman, 1987, 1991a), whereas Republicans tend to be conservatives (Eisenman \& Sirgo, 1991). Creative students might like Democrats, who tend to be more liberal, but they might also dislike Democrats since Democrats are not typically as radical and experimenting as creative people tend to be (Eisenman, 1991b). On the other hand, creative people tend to be much more accepting of outgroup members than do noncreative people. This seems to be a general lack of prejudice on the part of the creative person, such that the typical rejection of others who are different is avoided. In fact, creative people themselves are often "different," and this may result in empathy for others who are different. In Louisiana, where the data for this study were gathered, Republicans have, historically, been the outgroup and should thus be more likely rejected by noncreative students, who should, theoretically, react negatively to things that are different. Creative people should not show this kind of negative reaction to a politi-

\footnotetext{
The author is grateful to Keith Whitfield for his excellent statistical assistance and advice. Address reprint requests to R. Eisenman, Department of Psychology, McNeese State University, Lake Charles, LA 70609-1895.
}

cal party simply because it is different from the historically dominant party. Thus, from the standpoint of creative people's acceptance of outgroups, a totally different prediction would be made: Creative people will like Republicans more than will noncreative people.

Note that the two possible explanations-ideology or outgroup acceptance-lead to two totally different conclusions. The political ideology explanation leads to the expectation that creative students will dislike Republicans because Republicans are so often distant from the preferred style of creative people (i.e., creative people are often experimenting, radical, and risk-taking; see Barron, 1990; Eisenman, 1987, 1991a). The acceptance-of-outgroups explanation leads to the conclusion that creative students will be more accepting of Republicans than will noncreative students, because Republicans are, or at least have been until recently, something of an outgroup in the state where the research was conducted. It is less clear how creative and noncreative students would respond to like or dislike ratings of Democrats. On the one hand, Democrats tend to have something in common with creative people's outlooks by being more willing to accept minorities and experiment with social programs (Eisenman \& Sirgo, 1992; Sirgo \& Eisenman, 1990). However, it could be that creative people would see conventional politics as totally inconsistent with their world view, which may go beyond the views of the typical political scene, as manifested by disputes between the two parties. Thus, creative students may be indifferent to Democrats or possibly even hostile to them, seeing them as not going far enough or as being involved in something the students see as fruitless and alien. So, it is not as obvious how Democrats would be received in the like-dislike ratings of the creative or noncreative students.

\section{METHOD}

\section{Sample}

The sample consisted of $\mathbf{5 2}$ freshman and sophomore students at a Louisiana university. They were tested during their introduction to psychology class. 


\section{Procedure}

The students were asked to circle the word like or dislike, which appeared after the words Democrat and Republican. In response to student questions, the experimenter urged the students to select like or dislike, but they were told that was if they were unsure, then it was alright to omit an answer or otherwise respond differently, such as making a circle between like and dislike. As in previous research that used likedislike ratings (Eisenman, 1992), the data were omitted from analysis if the student did not follow the original request and circle either like or dislike.

For measuring creativity, each student was provided with a photocopy of 12 polygons varying in complexity from 4 to 24 points (Eisenman, 1991a). Complexity is defined by the number of points, including inward points and points pointing outward. One could also say that complexity is defined by the number of turns. With these polygons, "points" and "turns" mean the same thing. There were three symmetrical polygons of 4,8 , or 10 points, taken from Birkhoff (1933) and used extensively by the author in previous research (Eisenman, 1991a), and three each of 4-, 12-, and 24-point polygons, which had been chosen from those used by Vanderplas and Garvin (1959) and had originally been constructed by randomly connecting points on a $100 \times 100$ grid (Attneave \& Arnoult, 1956). Students were asked to circle their three most preferred shapes. A complexity score was obtained by adding up the number of points on each polygon circled.

As in recent research (Eisenman, 1992), it was decided to use a cutoff score of $\mathbf{4 0}$ points as an indication of preference for complexity. To obtain a score of 40 , a student would have to choose at least one 24point shape among his or her three most preferred. Then, if no other 24-point shapes were chosen, the student would have to choose at least one middle-complexity 12-point shape. Finally, a 4-point shape could be chosen to get a score of 40 . This cutoff score of 40 points ensures that someone said to prefer complexity truly does so. If a median split were used, for example, it might be possible, depending upon the sample, to get very low-complexity choices rated as "preference for complexity" because they were high (in the upper $50 \%$ of the sample). This does not seem desirable, since we wish to have subjects who truly prefer complexity in our preference-for-complexity group. Having a cutoff score of $\mathbf{4 0}$ achieves this goal, since one can get a score of $\mathbf{4 0}$ only by choosing a relatively high level of complexity, including at least one 24-point shape.

\section{RESULTS}

The results showed that Democrats were generally liked by a majority of the students. With 40 points used as the cutoff score for complexity, 27 of 35 low-creative students (preference at 39 points or less) liked Democrats, and 13 of 16 creative students liked Democrats. This yields a chi square of 0.49 , which is clearly not significant. However, for the like-dislike ratings of Republicans, 19 of 34 low-creative students liked Republicans, whereas a much more favorable 14 of 17 highly creative students indicated liking of Republicans. Creative students were significantly more likely to like Republicans than were less creative students $\left[\chi^{2}(1)=4.73, p=.028\right]$.

\section{DISCUSSION}

The findings support the outgroup explanation over the political ideology explanation. Creative students did not reject Republicans by indicating dislike, which should have been the case if their choices were made on the basis of political ideology, since the typical Republican ideology is much more conservative than the typical view of creative people (Barron, 1990; Eisenman, 1991b; Eisenman \& Sirgo, 1991, 1992). Rather, the creative students were more likely than the less creative students to be accepting of Republicans, as indicated by the greater use of like ratings with regard to Republicans. Since Republicans have, historically, been an outgroup in Louisiana, where the study was done, the creative students would appear to be showing support for the less accepted outgroup, which is consistent with the greater openness of creative people and the greater simplistic, prejudiced thinking of less creative subjects (including people who prefer simple polygons; see Eisenman, 1968, 1991a, 1992).

There are some issues that should be considered. First, since the sample was composed of university freshmen and sophomores, it may well be that this is a very apolitical group, whose choices on most things would be nonideological. Perhaps an older group would be more likely to choose on the basis of political beliefs and would possibly give different results. Second, although the connection between Republicans and conservatism has empirical support (Eisenman \& Sirgo, 1991, 1992), as does the tendency for many conservatives to be somewhat negative toward minorities (Eisenman, 1991b; Eisenman \& Sirgo, 1992; Sirgo \& Eisenman, 1990), it is likely that many people, creative or noncreative, do not know these things. Thus, when asked to indicate attitudes toward Democrats or Republicans, people make their choices on the basis of the knowledge they possess. We cannot assume that they have the same knowledge base as researchers do about things. Going back to the issue of freshmen and sophomore college students' being largely apolitical, it may be that the most relevant thing about Republicans to them is the largely outgroup status that Republicans have had in the state, especially until recent times.

The present study showed that creative students, as indicated by preference for complexity in polygons, made the somewhat surprising response that they liked Republicans more than did noncreative students. The explanation for this finding would seem to be that creative people are more accepting of outgroups than are noncreative people. However, other explanations might be possible, and other creativity measures could be utilized in future research.

\section{REFERENCES}

Attneave, F., \& Arnoult, M. D. (1956). Methodological considerations in the quantitative study of shape and pattern perception. Psychological Bulletin, 53, 452-471.

BARRON, F. (1990). Creativity and psychological health: Origins of personal vitality and creative freedom. Buffalo, NY: Creative Education Foundation Press.

Birkhoff, G. D. (1933). Aesthetic measure. Cambridge, MA: Harvard University Press.

EISENMAN, R. (1968). Complexity-simplicity preferences, involvement, and attitude change. Journal of Creative Behavior, 2, 128-132.

Eisenman, R. (1987). Creativity, birth order, and risk taking. Bulletin of the Psychonomic Society, 25, 87-88.

Eisenman, R. (1991a). From crime to creativity: Psychological and social factors in deviance. Dubuque, IA: Kendall/Hunt.

EISENMAN, R. (1991b). Gender and racial prejudice of conservative college women. Psychological Reports, 68, 450.

EISENMAN, R. (1992). Creativity, social and political attitudes, and liking or disliking David Duke. Bulletin of the Psychonomic Society, 30, 19-22.

EISENman, R. (in press). Creativity in prisoners: Conduct disorders vs. psychotics. Creativity Research Journal.

EISENMAN, R., \& SiRGO, H. B. (1991). Liberals versus conservatives: Personality, child-rearing attitudes, and birth order/sex differences. Bulletin of the Psychonomic Society, 29, 240-242.

EIsenman, R., \& SiRgo, H. B. (1992, March). Racial attitudes and voting behavior in the 1988 national elections. Paper presented at the annual meeting of the Southwestern Social Science Association, Austin, TX.

Sirgo, H. B., \& Eisenman, R. (1990). Perceptions of governmental fairness by liberals and conservatives. Psychological Reports, 67, 1331-1334.

Vanderplas, J. M., \& Garvin, E. A. (1959). The association value of random shapes. Journal of Experimental Psychology, 57, 147-154.

(Manuscript received July 6, 1992.) 